\title{
Role of Medical Sociology and Anthropology in Public Health and Health System Development
}

Sigdel $\mathbf{R}^{1}$

\section{Role of Medical Sociology in Public Health}

The medical sociology helps to identify and study social groups in their activities of maintaining and preserving health, alleviating or curing diseases. The social group is a social system whose components are interdependent. Medical sociology is concerned with the social facets of health and illness, social function of health institutions and organizations, the relationship of health care delivery to other social systems and social behavior of health personnel and consumers of health care. In brief, it's the study of relationships between health phenomena and social factors. Thus, in medical sociology health, illness and medical care are studied from sociological perspectives. (1)

The units of analysis in medical sociology are;the smallest social unit of relationships between doctor and patient, doctor and nurse and others, organizational unit includes hospitals, medical associations etc., social status which refers to occupational categories like doctor, nurse etc. and community and society where neighborhood health centre, public health centre and accessibility of primary health care can be studied. $(1,2)$

Every society has its own definition of health, illness and disease. The medical sociology helps in understanding distribution and aetiology of disease in the society, the social and cultural perspective on disease, roles and attitude towards treatment. Medical sociology contributes to social aspects of medicine, for e.g. social factors involved in illness, the behavior of patients, medical professionals and other health workers as well as different types of medical organizations. Social science is concerned with human relationships either interpersonal relationships, individual personality or in context with its external milieu. Social science concerns with the people, who are either healthy or ill, but not with the disease itself. In more precise terms, it deals with the society in which people live in groups and thus deals with its structure, function, change and action. (3)

The contribution of medical sociology is in two spheres: 1

$$
\begin{aligned}
& \text { I. Sociology in medicine } \\
& \text { II. Sociology of medicine }
\end{aligned}
$$

The sociology in medicine deals with analysis of aetiology of health disorders, differences in social attitude towards health and the recognition of relation of social variables like sex and
${ }^{1}$ Department of Community Medicine and Public Health, Maharajgunj Medical Campus, Institute of Medicine, TU, Nepal

age to the incidence of a specific health disorder. So, this is a type of applied research motivated by a medical problem rather than a sociological problem.

The sociology of medicine deals with organization's role, relationships, norms, values and beliefs of medical practice as a form of human behavior. Here, the social processes that occur in a medical setting are studied. Thus, sociology of medicine is research and analysis of medical environment from a sociological perspective. Thus, in short medical sociology covers the following aspects of public health:

i. Social determinants and distribution of disease

ii. Attitudes and behavior of individuals and also individuals in group settings towards health and illness and this in turn decides their concept of health and illness, health seeking behavior and their level of acceptance towards modern form of medicine, their perceived health needs and their acceptance or rejection of various health programs.

iii. It also studies the social environment of medicine and helps to design the curricula of trainings for health personnel.

iv. It also studies the relationship between health provider and consumer, and thus decides the preference of consumer for a particular type of service as well as compliance of the consumer to the physician's advice.

v. It studies the medical organizations in structural and functional manner.

As we can see from above, medical sociology helps to understand the various factors related with a healthy or ill person and not the disease process itself and its specific aetiology. Thus, its contribution is more towards understanding the problem from a preventive and promotive aspect.

\section{Role of Medical Anthropology in Public Health}

Medical anthropology is the cross cultural study of medical systems and the study of bio-ecological and socio-cultural factors that influence the incidence of health and disease now and throughout human history. The areas where the medical anthropologists do research are human evolution,

CORRESPONDENCE: Assist. Prof. Ramesh Sigdel, Department of Community Medicine and Public Health, Maharajgunj Medical Campus, Institute of Medicine, TU, Nepal 
anatomy, paediatrics, epidemiology, mental health, drug abuse, definition of health and disease, training of medical personnel, medical bureaucracies, hospital organization and operations, the doctor patient relationship and process of bringing scientific medicine to users of traditional medicine. $(1,4)$

The medical anthropology can be studied as a bi-polar process whose one pole is biological in which one studies human growth and development, role of disease in human evolution and study of disease of ancient man. The second is sociocultural pole where one studies traditional medical systems, illness behaviour, doctor patient relationship, introduction of western medicine to traditional societies and in between this there is epidemiology and cultural ecology. (5) So, medical anthropology encompasses the study of medical phenomena as they are influenced by social and cultural factors and social and cultural phenomena as they are influenced by these medical aspects. Another definition states that medical anthropology is concerned with the biocultural understanding of man and his works in relation to health and medicine. (6)

Medical anthropology studies the relationship between human evolution and disease in the past, the biological and cultural determinants of disease, health and health care, the basis and effectiveness of traditional health care systems and suggests ways to integrate modern medicine into traditional societies.

Hence, medical anthropology doesn't study the relationship of individual person to disease but studies the relationship between the biological and cultural characteristics of a group(ethnic or racial) and its resistance of susceptibility to various diseases in view of different genetic constitution. (7) It studies the traditional medical systems but not the modern systems of medicine.

It helps to understand the disease prevalence and susceptibility to the genetic make-up of a man belonging to a particular race or ethnicity, impact of disease on human evolution and the impact of these inherent ethnic and racial differences on the functioning and acceptability of health care. (8)

\section{Role of Medical Sociology and Anthropology in Health System Development}

Public health as seen from the eyes of comprehensive primary health care mentioned in Alma Ata declaration covers the following aspects that can be analyzed from social and anthropological perspective. $(9,10)$

i. It sees health as a process in human development and states that it cannot be achieved in isolation without associated socio-economic development.

ii. It strongly affirms that health which is the complete state of physical, social and mental well being and not merely the absence of disease and infirmity is the fundamental human right and to achieve the highest level of health should be a world-wide social goal.

iii. For health it lays emphasis on all the aspects of health care that is, preventive, promotive, curative and rehabilitative.

iv. Its shape is determined by social goals like quality of life and maximum health benefits to the greatest number of people and advises to attain these goals by social means like community participation.

v. It lays emphasis on essential health care which is accessible, affordable and acceptable by the people and with their full participation. This health care has to be scientifically sound and socially acceptable. It requires co-ordinated efforts from all other related sectors.

vi. It is based on the economic, socio-cultural and political conditions of a country and it promotes equity.

Thus, primary health care as a means of public health looks after the health of the people not only by providing health services or taking the help of health personnel and health services. It lays stress in the overall development process as health, social and economic to desired results in the other sectors. (11) The benefit of overall development trickles down to societies, from there to individual families and lastly the individuals themselves. Hence, the name also benefits its description, the comprehensive primary health care. This care is more action oriented with input from various sectors like medical sociology and medical anthropology to meet the health needs of the public health system development in a better way.

\section{References:}

1. Gartaulla RP. Text Book of Medical Sociology and Medical Anthropology; Research Centre for Integrated Development, Nepal (RECID/Nepal), Kathmandu, Nepal; 2008

2. Cockerham, W. C. Medical Sociology, 8th edition. Englewood Cliffs, NJ: Prentice Hall;2000

3. Annandale, E. The Sociology of Health and Medicine: A Critical Introduction. Malden, MA: Polity Press;1998

4. Freidson, E. Professional Dominance: The Social Structure of Medical Care. New York: Atherton Press;1970Illich, I. Limits to Medicine. Toronto: McClelland and Stewart;1976

5. Coleman, J. S. Foundations of Social Theory. Cambridge, MA: Belknap Press;1994

6. Durkheim, E. The Rules of Sociological Method. New York: Free Press; 1982

7. Marx, K. Grundrisse: Foundations of the Critique of Political Economy. New York: Vintage Books;1973

8. Martin, E. The Woman in the Body. Boston: Beacon Press;1987

9. McKeown, T. The Role of Medicine: Dream, Mirage or Nemesis? London: Nutfield Provincial Hospitals Trust;1976

10. Sociology in Public Health.[cited 2012 July 25];Available from http://www.enotes.com/sociology-public-health-reference/ sociology-public-health.

11. Declaration of Alma- Ata(1978).[cited 2012 July 21]; Available from http://en.wikipedia.org/wiki/Alma_Ata_Declaration. 